\title{
Investigating the role of conflict management strategy on development of cooperative management
}

\author{
Hosseinali Aziziha $^{a}$, Ali Khodsetan ${ }^{b}$, Mahsan Hajirasouliha ${ }^{a}$, Ashkan Faraji ${ }^{a}$, Milad Isakhani Zakaria ${ }^{c}$, \\ and Seyed Shahab Mousavi ${ }^{{ }^{*}}$
}

${ }^{a}$ Department of Management and Accounting, South Branch, Islamic Azad University, Tehran, Iran

${ }^{b}$ Department of Management and Accounting, Allameh Tabatabaee University, Tehran, Iran

${ }^{c}$ Department of Management and Accounting, University of Tehran, Tehran, Iran

\section{H R O N I C L E \\ A B S T R A C T}

Article history:

Received October 28, 2013

Received in revised format

25 November 2013

Accepted 22 January 2014

Available online

January 252014

\section{Keywords:}

Conflict management

Cooperative culture

Auto industry

\begin{abstract}
This paper presents an empirical study to investigate the effect of conflict management strategies on development of cooperative culture in one of Iranian auto industries. The proposed study adopts a Putnam and Wilson's questionnaire (1982) [Putnam, L. L., \& Wilson, C. E. (1982). Communication strategies in organizational conflicts: Reliability and validity of a measurement scale. Communication Yearbook, 6, 629-652.] for measuring different components of conflict management. In addition, the study also designs a questionnaire for measuring cooperative culture. Cronbach alphas are calculated for conflict management and cooperative cultures as 0.76 and 0.79 , respectively. Using Spearman correlation ratio as well as regression technique, the study has determined that three components of conflict management strategies including cooperation, competition and compromise could significantly contribute of development of cooperative culture.
\end{abstract}

\section{Introduction}

Conflict in any society reduces efficiency and there are many studies to reduce any existing conflict as much as possible. Research investigating the effect of culture on conflict management and resolution behaviors has indicated that individualism and collectivism may impact a person's style of conflict resolution behavior (Thomas, 1992). However, these findings have not been linked to the associated constructs of vertical and horizontal individualism and collectivism as defined by Triandis (1994), which build the concept of accepting authority. Some studies indicate the existence of a strong parallel between the vertical and horizontal dimensions of individualism and collectivism and power distance (Kaushal \& Kwantes, 2006). The salience of this power variable could be different

\footnotetext{
*Corresponding author

E-mail addresses: moosavi.shahab@ymail.com (S. S. Mousavi) 
from one culture to another, and impacts not only the nature of the conflict process itself, but also the conflict resolution strategies adopted. Kaushal and Kwantes (2006), for instance, investigated the role of culture and personality in choice of conflict management strategy. Prenzel and Vanclay (2014) investigated the contribution of the methodological approach implemented in social impact assessment (SIA) to conflict management. They considered conflict as a process, which has its own dynamic by conceptualizing the process and highlighting the importance of communication in managing conflict through game theory. They explained the potential use of SIA in preventing, managing and resolving conflict where the focus was on the participatory character of SIA and the role of public media. Mazaheri et al. (2011) studied the effect of pre-existing attitude and conflict management style on customer satisfaction with service recovery and concluded that a cooperative recovery style and exceeding expectations would be necessary to satisfy customers. Lam and Chin (2005) identified and prioritized critical success factors for conflict management in collaborative new product development.

\section{The proposed study}

The proposed study of this paper investigates the relationship between conflict management strategies on development of cooperative culture in auto industry. The study has been accomplished in one of subsidiaries of Iran Khodro named Tom-Irankhodro. There were 440 employees in this auto industry and the sample size is calculated as follows,

$$
n=\frac{N \times z_{\alpha / 2}^{2} \times p \times q}{\varepsilon^{2} \times(N-1)+z_{\alpha / 2}^{2} \times p \times q},
$$

where $N$ is the population size, $p=1-q$ represents the yes/no categories, $z_{\alpha / 2}$ is CDF of normal distribution and finally $\varepsilon$ is the error term. Since we have $p=0.5, z_{\alpha / 2}=1.96$ and $N=440$, the number of sample size is calculated as $n=206$. The proposed study adopts a Putnam and Wilson's questionnaire (1982) for measuring different components of conflict management. In addition, the study designs a questionnaire for measuring cooperative culture. There are five hypotheses associated with the propsoed study of this paper as follows,

1. Competition strategy influences on cooperative management, significantly.

2. Prevention strategy influences on cooperative management, significantly.

3. Compromise strategy influences on cooperative management, significantly.

4. Compatibility strategy influences on cooperative management, significantly.

5. Cooperation strategy influences on cooperative management, significantly.

The proposed study uses Cronbach alphas to validate the overall questionnaires and Cronbach alphas are calculated for conflict management and cooperative cultures as 0.76 and 0.79 , respectively, which are well above the minimum acceptable levels. Fig. 1 demonstrates the summary of the proposed study of this paper.

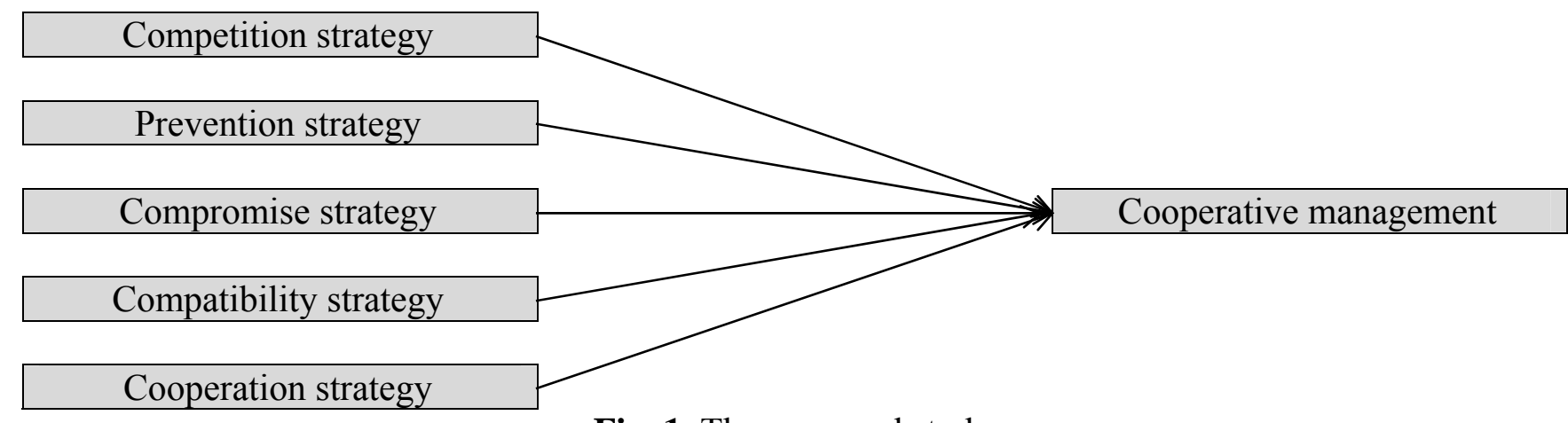

Fig. 1. The proposed study 
The proposed study has applied Kolmogorov-Smirnov in order to understand whether the data are normally distributed or not and the results did not confirm the normality of the data. Therefore, we use Spearman correlation test to examine the relationship between different components of the survey.

\subsection{Personal characteristics of the participants}

In our survey, $22.1 \%$ of the participants were female and $77.9 \%$ of them were male. In terms of their job characteristics, $12.6 \%$ of them were middle-level managers and $87.4 \%$ of them were regular staff.

Fig. 2 shows other characteristics of the participants.

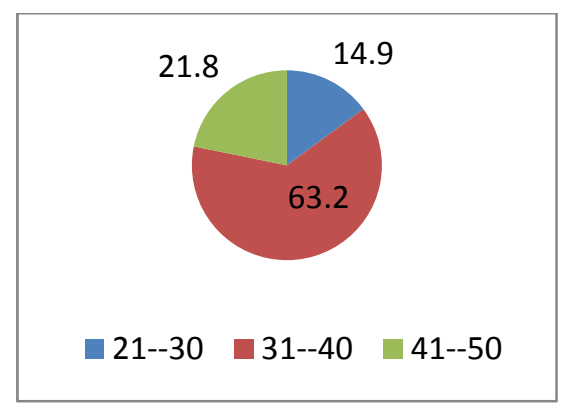

Age

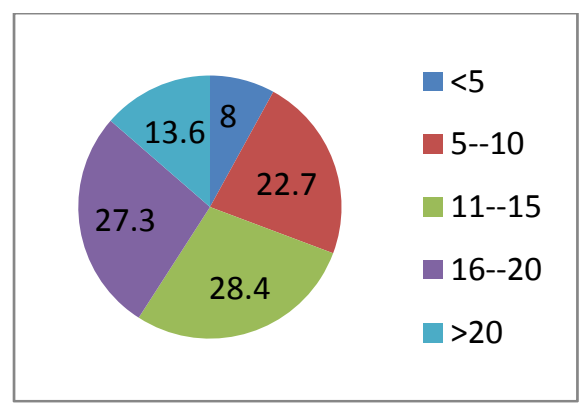

Job experience

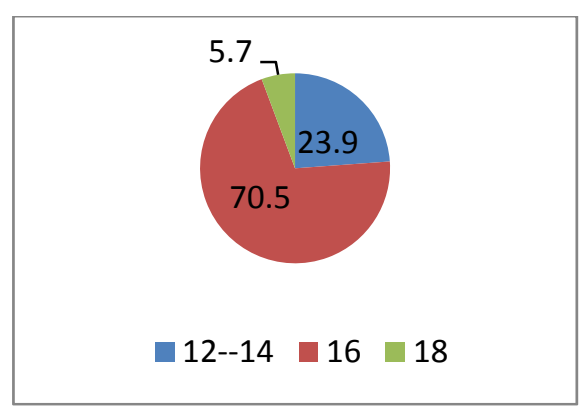

Years of education

Fig. 2. Personal characteristics of the participants

As we can observe from the results of Fig. 2, most participants were middle age, they have some university education and most of them have good job experiences.

\section{The results}

In this section, we present details of our findings on testing the effects of five conflict management strategies on development of cooperative culture.

\section{Table 1}

The summary of Spearman correlation between organizational conflict and cooperative culture

\begin{tabular}{llccc}
\hline Hypothesis & The relationship & $\mathrm{r}$ & $\mathrm{Sig}$. & Result \\
\hline 1 & Competition strstegy and cooperative cutlure & -0.304 & 0.004 & Confirmed \\
2 & Prevention strategy and cooperative culture & -0.271 & 0.001 & Confirmed \\
3 & Compromise strategy and cooperative culture & 0.185 & 0.001 & Confirmed \\
4 & Compatibility strategy and cooperative culture & 0.236 & 0.023 & Confirmed \\
5 & Cooperation strategy and cooperative culture & 0.312 & 0.001 & Confimed \\
\hline
\end{tabular}

The results of Table 1 show that competition strategy maintains negative correlations with cooperative culture $(r=-0.304$, Sig. $=0.004)$, preventional strategy $(r=-0.271$, Sig. $=0.001)$. However, compromise strategy has positive and meaningful relationship with cooperative cultre $(\mathrm{r}=0.185$, Sig. $=0.001)$. There is also a positive and meaningful relationship between compatibility strategy and cooperative culture $(r=0.236$, Sig. $=0.023)$. Finally, the the implementation of Spearnam correlation has indicated a positive and meaningful relationship between coopertion stratgey and cooperative culture $(\mathrm{r}=0.312$, Sig. $=0.001)$. We have performed a stepwise regression analysis between organizational conflict and cooperative cultre where cooperative culture is dependent variable and organizational conflict components are as independent variables and the results are summarized in Table 2 as follows, 
Table 2

The summary of stepwise regression model

\begin{tabular}{cccccc}
\hline Variables & Coefficient & Standard error & Standard coefficient & t-value & Sig. \\
\hline Intercept & 65.192 & 3.649 & & 19.948 & 0.000 \\
Cooperation strategy & 0.511 & 0.186 & 0.295 & 3.451 & 0.002 \\
Competition strategy & -0.409 & 0.130 & -0.204 & -2.127 & 0.009 \\
Compromise strategy & 0.473 & 0.162 & 0.271 & 3.839 & 0.001 \\
\hline
\end{tabular}

The results of Table 2 indicate that development of cooperative culture has positive relationship with cooperation strategy $(\beta=0.51)$, compromise stratgey $(\beta=0.473)$. In addition, the results indicate a negative and meaningful relationship between development of cooperative culture and competition strategy $(\beta=-0.409)$. However, the implementation of the regression analysis did not confirm the relationship between prevention and development of cooperative culture.

\section{Conclusion}

In this paper, we have presented an emprical investigation to study the effect of conflict management on development of cooperative culture in Iranian auto-industry. The study has applied standard questrionnaire for measuring conflict management and developed a questionnaire for measuring cooperative culture. The results of Spearman correlation test have indicated that competition strategy maintained negative correlations with cooperative culture and preventional strategy. However, compromise strategy had positive and meaningful relationship with cooperative cultre. There was also a positive and meaningful relationship between compatibility strategy and cooperative culture. The implementation of Spearnam correlation has also indicated a positive and meaningful relationship between coopertion stratgey and cooperative culture. The implementation of stepwise regression analysis has also indicated that development of cooperative culture has positive relationship with cooperation strategy and compromise stratgey. In addition, the results have also indicated a negative and meaningful relationship between development of cooperative culture and competition strategy. However, the analysis did not confirm the relationship between prevention and development of cooperative culture.

\section{Acknowledgement}

The authors would like to thank the anonymous referees for constructive comments on earlier version of this paper, which has contributed to the quality of our presentation.

\section{References}

Kaushal, R., \& Kwantes, C. T. (2006). The role of culture and personality in choice of conflict management strategy. International Journal of Intercultural Relations, 30(5), 579-603.

Lam, P.K., \& Chin, K.S. (2005). Identifying and prioritizing critical success factors for conflict management in collaborative new product development. Industrial Marketing Management, 34(8), 761-772

Mazaheri, E., Basil, D. Z., Yanamandram, V., \& Daroczi, Z. (2011). The impact of pre-existing attitude and conflict management style on customer satisfaction with service recovery. Journal of Retailing and Consumer Services, 18(3), 235-245.

Putnam, L. L., \& Wilson, C. E. (1982). Communication strategies in organizational conflicts: Reliability and validity of a measurement scale. Communication Yearbook, 6, 629-652.

Prenzel, P.V., \& Vanclay, F. (2014). How social impact assessment can contribute to conflict management. Environmental Impact Assessment Review, 45, 30-37.

Triandis, H.C. (1994). Culture and social behavior. New York, NY: McGraw-Hill.

Thomas, K. W. (1992). Conflict and conflict management: Reflections and update. Journal of Organizational Behavior, 13(3), 265-274. 